\title{
INFLUENCE OF STRUCTURE ON THE PROPERTIES OF POLYPROPYLENE COPOLYMERS AND TERPOLYMERS
}

\author{
Susana Caveda ${ }^{1}$, Ernesto Pérez ${ }^{2}$, Enrique Blázquez-Blázquez ${ }^{2}$, Begoña Peña ${ }^{1}$, Rafael \\ van Grieken $^{3}$, Inmaculada Suárez ${ }^{3}$, Rosario Benavente ${ }^{2}$
}

${ }^{1}$ CTR Repsol, Móstoles, 28931-Madrid, Spain.

${ }^{2}$ Instituto de Ciencia y Tecnología de Polímeros, ICTP-CSIC, Juan de la Cierva 3, 28006Madrid, Spain.

${ }^{3}$ Escuela Superior de Ciencias Experimentales y Tecnología, Universidad Rey Juan Carlos, 28933 Móstoles-Madrid, Spain.

E-mail: $\underline{\text { rbenavente@ictp.csic.es }}$

\begin{abstract}
A set of Ziegler-Natta copolymers of iPP with ethylene or with 1-butene, and terpolymers with both counits have been characterized, devoting special attention to the effect of composition and processing conditions on the crystal structure and on the final properties. DSC and X-ray diffraction is used to study the polymorphism of copolymers and terpolymers. Comonomer insertion interrupts the isotactic sequences, acting as a structural defect, and the formation of $\gamma$ form is enhanced in the interval of studied compositions. Moreover, crystallinity decreases and crystal structure is modified. Comonomer type and concentration determine the extent of these modifications, resulting on important changes in macroscopic properties. An important aspect to be considered is the higher ability of 1-butene units to be incorporated in the iPP crystals in relation to ethylene counits. From the balance of different properties, possible applications are suggested for the various types of samples. For instance, the excellent optical properties of the analyzed terpolymers make them very attractive for applications such as transparent film or packaging.
\end{abstract}

\section{Key words}

Isotactic polypropylene copolymers and terpolymers; polymorphism; X-ray diffraction; DSC, mechanodynamical properties, mechanical properties, optical properties. 


\section{Introduction}

Isotactic polypropylene, iPP, is a widely used thermoplastic, combining exceptional mechanical properties and low cost, and is used in a wide variety of applications. Polypropylene versatility is mainly due to its structure and the ease to be modified in various ways in order to obtain enhanced properties. Particularly, crystallization strongly influences final supermolecular structure and thus properties of polymorphic polymers.

Moreover, iPP exhibits a remarkable polymorphism, depending on microstructural features, crystallization conditions and other factors like the use of specific nucleants. Thus, three different polymorphic modifications, $\alpha, \beta$, and $\gamma$ have been reported ${ }^{[1-4]}$, which can be induced conveniently. In addition, a new trigonal form has been described in the case of copolymers of iPP with high contents of 1-hexene or 1- pentene as comonomers. ${ }^{[5-10]}$

Moreover, a kind of mesomorphic form has been found to appear not only in homopolymer but also in different random copolymers, with comonomers such as ethylene, 1butene, 1-pentene and other $\alpha$-olefin copolymers. ${ }^{[11-14]}$

Among the different paths for modifying the ability to crystallize the iPP and the type of polymorph desired, this paper focuses on the introduction of comonomer units. Comonomer type and concentration determine the extent of these modifications, resulting on important changes on macroscopic properties. Comonomer acts as a structural defect, interrupting the isotactic sequence, therefore reducing the global crystallinity and modifying the crystal structure. Additionally, comonomer insertion, together with specific crystallization conditions, enhances the formation of $\gamma$ form. ${ }^{[15-19]}$

Moreover, the tolerance of counits by the crystalline entities is also an important factor. Thus, the introduction of 1-butene units into the iPP crystal lattice is high, due to its similarity with propylene monomer, although crystals formed are not as perfect as those created with polypropylene homopolymer. This crystal structure results on a great balance of mechanical and optical properties. Ethylene is also incorporated into polypropylene crystal lattice, but to a lower extent than 1-butene. ${ }^{[20,21]}$

On the other hand, longer chain $\alpha$-olefin copolymers, such as 1-hexene and 1-octene, present different morphology and crystallization kinetics than ethylene and 1-butene copolymers. They are excluded from the crystal, due to their strong steric hindrance caused by molecular size, and incorporated in greater amount to the amorphous fraction. ${ }^{[22]}$

Ethylene and 1-butene copolymers have been widely studied in the literature. It is not the case of the terpolymers, a family of polymers that has experimented an increasing interest 
in recent years. ${ }^{[23-26]}$

Therefore the aim of this paper is to study the structural differences and related macroscopic properties of a selected group of terpolymers, with different comonomer content, comparing the results with those of a set of ethylene and 1-butene copolymers with an equivalent comonomer content. All polymers have been synthesized in a laboratory scale and are analyzed using different characterization and property analysis methods. The investigation endeavors to reveal the influence of the comonomer in the crystal structure as well as the effect of thermal treatment. Also, the structural differences are intended to relate to macroscopic properties of terpolymers and copolymers, which determine their commercial applications. 


\section{Experimental part}

The characteristics of the samples for the present study are listed in Table 1, including

the comonomer content obtained by ${ }^{13} \mathrm{C}-\mathrm{NMR}$ and their molecular weights measured by gel permeation chromatography. All these polymer samples have been supplied by Repsol and were produced at laboratory scale.

Films of the original samples were obtained by compression molding in a Collin press between hot plates $\left(200{ }^{\circ} \mathrm{C}\right)$ at a pressure of $10 \mathrm{MPa}$ for $4 \mathrm{~min}$. Two different thermal treatments were applied. The first thermal history, labeled S, consisted of a slow cooling (ca. $1.5^{\circ} \mathrm{C} / \mathrm{min}$ ) from the molten state down to room temperature, at the inherent cooling rate of the press, after the power was switched off. The second one, named Q, applied a fast cooling (ca. $200{ }^{\circ} \mathrm{C} / \mathrm{min}$ ) between plates refrigerated with cold water after the melting of the material in the press. The specimens for the different samples are designated as follows: PR standing for "Polypropylene Random copolymer", followed by the letter E or B to indicate type of comonomer, ethylene or 1-butene respectively, followed by the mol percentage of comonomer. The terminology used for the terpolymers is either PRT or indicating the molar content in the two copolymers. The corresponding code for the cooling conditions, Q or S, is indicated when pertinent. The sample code for the homopolymer is simply HOMO.

The thermal properties were analyzed in a TA Q100 calorimeter connected to a cooling system and calibrated with different standards. The sample weight ranged from 5 to 7 mg. Samples were firstly heated from -45 to $200{ }^{\circ} \mathrm{C}$ at a heating rate of $20{ }^{\circ} \mathrm{C} / \mathrm{min}$ and then cooled down to $-45^{\circ} \mathrm{C}$ at the same rate, followed by a second heating. For crystallinity determinations, fc DSC, a value of $168 \mathrm{~J} / \mathrm{g}$ has been taken as the enthalpy of fusion of the $\alpha / \gamma$ modification of iPP with $100 \%$ WAXD crystallinity. ${ }^{[18,27,28]}$

Wide-angle X-ray diffraction (WAXS) patterns were recorded at room temperature in the reflection mode by using a Bruker D8 Advance diffractometer provided with a PSD Vantec detector (from Bruker, Madison, Wisconsin). $\mathrm{Cu} \mathrm{K}_{\alpha}$ radiation $(\lambda=0.15418 \mathrm{~nm}$ ) was used, operating at $40 \mathrm{kV}$ and $40 \mathrm{~mA}$. The parallel beam optics was adjusted by a parabolic Göbel mirror with horizontal grazing incidence Soller slit of $0.12^{\circ}$ and $\mathrm{LiF}$ monochromator. The equipment was calibrated with different standards. A step scanning mode was employed for the detector. The diffraction scans were collected within the range of $2 \theta=3-43^{\circ}$, with a $2 \theta$ step of $0.024^{\circ}$ and $0.2 \mathrm{~s}$ per step.

The X-ray determinations of the degree of crystallinity were performed by subtraction of the corresponding amorphous component by comparison with the totally amorphous profile 
of an elastomeric PP sample. ${ }^{[29,30]}$

The relative content of $\gamma$ - phase, $\mathrm{K}_{\gamma}$, can be evaluated by the following equation ${ }^{[31]}$ :

$$
K_{\gamma}=\frac{H_{\gamma(117)}}{H_{\gamma(117)}+H_{a(130)}}
$$

where $H_{\gamma(117)}$ represents the area of the $\gamma(117)$ reflection and $H_{\alpha(130)}$, the area of the (130) diffraction.

Dynamic mechanical relaxations were measured with a Polymer Laboratories MK II Dynamics Mechanical Thermal Analyzer, working in a tensile mode. The storage modulus E', loss modulus E", and the loss tangent $\tan \delta$ of each sample were obtained as function of temperature over the range from -140 to $150{ }^{\circ} \mathrm{C}$, at fixed frequencies of $1,3,10,30 \mathrm{~Hz}$, and at a heating rate of $1.5^{\circ} \mathrm{C} / \mathrm{min}$. Strips of $2.2 \mathrm{~mm}$ wide and $15 \mathrm{~mm}$ length were cut from the molded sheets.

A Vickers indentor attached to a Leitz microhardness $(\mathrm{MH})$ tester was used to perform microindentation measurements. The experiments were carried out at $25^{\circ} \mathrm{C}$, with contact load of $0.98 \mathrm{~N}$ and $25 \mathrm{~s}$. MH values (MPa) were calculated according to the following relationship [32]:

$$
\mathrm{MH}=2 \sin 68^{\circ}\left(\mathrm{P} / \mathrm{d}^{2}\right)
$$

where $\mathrm{P}(\mathrm{N})$ is the contact load and $\mathrm{d}(\mathrm{mm})$ is the diagonal length of the projected indentation area.

Stress-strain measurements were performed using an Instron dynamometer equipped with a load cell and an integrated digital display that provided force determinations. Dumbbell samples with an effective length of $15 \mathrm{~mm}$ and a width of $1.9 \mathrm{~mm}$ were cut from the compression-molded sheets. These specimens were then stretched at a strain rate of 10 $\mathrm{mm} / \mathrm{min}$ at $23{ }^{\circ} \mathrm{C}$, and Young's modulus (E), yield stress $\left(\sigma_{\mathrm{Y}}\right)$ and strain $\left(\varepsilon_{\mathrm{Y}}\right)$ and stress and strain at break $\left(\sigma_{\mathrm{B}}\right.$ and $\left.\varepsilon_{\mathrm{B}}\right)$ were determined. The Young's modulus was measured from the slope of the curve at very small deformations (the initial linear part of the curve). On the other hand, the yield stress and strain values were usually calculated from the maximum on the stress-strain curves obtained. The values reported for Young's modulus, yield stress and strain are averages from, at least, three different specimens of each sample.

Optical properties were measured with a BYK Gardner model Haze-Gard Plus. To quantify transparency, three parameters are used: transmission of visible light (TGLV), haze and clarity as ASTM D 1003. Haze is defined as the percentage of light that deviates from the direction of the incident beam an angle greater than $2.5^{\circ}$, and clarity defines, analogously, as the percentage of light transmitted that deviates from the direction of the incident beam an 
angle lower than $2.5^{\circ}$.

\section{Results and Discussions}

\subsection{X-ray diffraction: Influence of comonomer nature on crystal structure}

\subsubsection{Samples with Q treatment:}

The X-ray diffractograms of the different samples rapidly cooled from the melt are shown in figure 1a. As expected, the homopolymer exhibits the diffractions characteristic of the $\alpha$ modification and the other copolymers and the terpolymer also exhibit the same peaks corresponding to the $\alpha$ phase, whose main diffraction peaks appear at $2 \theta$ values of $14.1,16.9$, $18.4,21.1$ and $25.8^{\circ}$ corresponding to the (110), (040), (130), (111), and $(040,131)$ reflections of the $\alpha$ modification of iPP $[33,34]$. The diffraction angles for the studied samples with $\mathrm{Q}$ treatment are indicated in Table 2. The $\alpha$-modification is not the most kinetically favored, nor the most thermodynamically stable, but nonetheless is the one that reaches the best compromise between those criteria, therefore being the most common form observed in polypropylene. ${ }^{[35]}$

It is observed in Table 2 that diffractions for 1-butene copolymers and terpolymers show a displacement to lower angles (higher spacings), as a consequence of the distortion of the crystal cell produced by the introduction of comonomer. This effect is stronger on 1butene copolymers than in terpolymers, and is not observed in ethylene copolymers, which indicates that 1-butene comonomer is introduced in the crystal lattice to a higher extent than ethylene, expanding the crystal cell. This conclusion is consistent with other authors that reported the similarity between isotactic polypropylene and polybutene conformations, which facilitates the inclusion of 1-butene in the iPP crystal structure. ${ }^{[35-40]}$ Ethylene comonomer, due to its small size, is not excluded from the crystal lattice, but it interrupts the iPP helix, shortening the crystal sequence and incorporating these distorted sequences to the amorphous fraction of the polymer. ${ }^{[37,41,42]}$

Figure 1a also shows the totally amorphous profile, amPP, of an elastomeric PP sample ${ }^{[30]}$, in this case scaled to account for the amorphous component corresponding to the terpolymer. By subtraction of this amorphous component (adequately scaled for each sample), the pure crystalline profiles (shown in figure $1 \mathrm{~b}$ ) can be obtained, as well as the overall X-ray

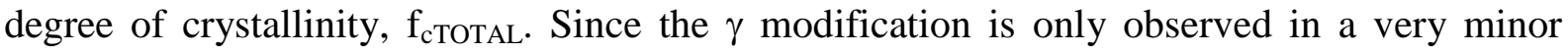
proportion in some cases, this overall degree of crystallinity corresponds almost entirely to the $\alpha$ form. The corresponding values are shown in Table 3 . 
The crystal size in the (110) direction, lc (110), has been also determined from the width at half height of the corresponding diffraction, calculated through Scherrer equation. ${ }^{[43]}$ These values are also indicated in Table 3 .

The overall crystallinity decreases with comonomer content, both in copolymers and terpolymers, as is shown in Figure 2. Also a significant decrease in crystal size stands out with increasing comonomer content (Figure 3). In Q samples, rapidly crystallized from the melt, the comonomer nature has small influence, since global crystallinities and crystal sizes of the three types of products present similar values. Only a remarkable difference is seen in the crystal size of the homopolymer, which is higher than any of the copolymers studied, as expected.

\subsubsection{Samples with $S$ treatment}

When the samples are slowly cooled from the melt, additional diffractions are observed, corresponding to the $\gamma$ phase of the iPP polymorph. The one around $20^{\circ}$, corresponding to the (300) reflection, is the most prominent, as observed in Figure 4, where the pure crystalline profiles, after subtraction of the amorphous component, are shown for the different samples.

The position of the various diffraction peaks are indicated in Table 2 for S-samples. Data show a movement to lower angles on butene copolymers with respect to homopolymer, due to the distortion of the crystal lattice produced by the comonomer incorporation to the crystal cell.

All S-samples present a global crystallinity higher than Q-samples, since longer crystallization time enables greater crystal growth.

1-Butene copolymers show higher crystallinity than ethylene copolymers and terpolymers at all comonomer contents. S-homopolymer shows superior crystallinity than any of the other copolymers, which was not observed in Q-samples.

By using eq. 1, the overall degree of crystallinity, $\mathrm{f}_{\mathrm{c} \text { тотАL }}$, can be divided into the two components for the $\alpha$ and $\gamma$ forms. The corresponding values are also shown in Table 3 .

It was not possible to determine crystal size $l c(110)$ on S samples, since position of diffraction (110) on monoclinic crystal $\alpha$ concurs with position of the diffraction (111) in the orthorhombic crystal $\gamma$.

The $\gamma$ phase is generally known to be generated by the introduction of chain defects or chemical heterogeneity caused by atacticity and the presence of comonomer units in the 
chain. From the results in Figure 5 it follows that those copolymers with ethylene exhibit higher content of $\gamma$ phase than 1-butene copolymers. Published works about the behavior of these two types of copolymers show the influence of the different stereodefects (isolated rr triads), ethylene and butene comonomeric units on the crystallization of $\alpha$ and $\gamma$ forms of iPP. Both copolymers crystallize from the melt as mixtures of $\alpha$ and $\gamma$ forms, depending on the crystallization temperature. In the case of 1-butene copolymers, the content of $\gamma$ form decreases at higher contents of comonomer [20]. Another important information deduced from Figure 5 is that the highest values of $\gamma$ crystallinity are shown by the terpolymers.

The presence of comonomer causes major structural defects in the polymer chain, which leads to shorter crystallizable sequences, favoring the formation of $\gamma$-crystals. This result is also in line with the work of other researchers $[15,44]$.

It is also important to remark that the intensity of the different diffractions and therefore the overall content of crystallinity hardly changes with the $5 \%$ mol counits of the analyzed comonomers and terpolymer, and independently of the thermal treatment, in relation to the homopolymer. In fact, the results in Table 3 indicate crystallinity differences smaller than 0.05 , the differences being especially small in the case of the Q specimens. When comonomer content increases to higher contents the crystallinity decrease is more notable.

This behavior is well different in the case of copolymers with 1-hexene (or higher 1olefins) where the crystallinity decreases very much with the comonomer content, in such a way that for a similar content of comonomer, $5 \mathrm{~mol} \%$, the degree of crystallinity falls down to 0.25 [45]. The origin of this different behavior shall be found in the fact that ethylene and 1-butene counits are able to cocrystallize in some extent with propene, independently of the thermal treatment. Nevertheless, different proportions of ethylene and butene units are included in crystals of the $\alpha$ and $\gamma$ form of iPP [31].

\subsection{Thermal analysis}

\section{2.1 Samples with $Q$ and $S$ treatment:}

DSC analysis was performed in the film samples prepared by compression-molding. Figure 6 shows the DSC first melting curves corresponding to the different samples with the two thermal treatments, and Table 4 collects the results for the different transitions of the samples with the two thermal treatments.

Glass transition, melting temperature and crystallization of a polymer are closely related to its microstructure and the processing conditions. The first important difference observed in Table 4 is the clear decrease in the glass transition temperature when counits are 
present. Moreover, the glass transition (not shown in Figure 6) is also sensitive to the thermal treatment applied (see below).

On the other hand, the copolymerization diminishes both the melting temperature and the enthalpy of melting in relation with the pure homopolymer. Although ethylene and 1butene can cocrystallize to some extent in the iPP crystals, however above certain limits those counits prevent the crystallization process by shortening the length of the crystallizable propylene sequences [19]. The compromise between cocrystallization and the limitation of the crystal sequences in the copolymerization of propene with ethylene and 1-butene allows controlling the crystallization process and therefore the mechanical properties. In the present case, it can be observed that the melting temperature decrease is lower for 1-butene copolymers than for ethylene copolymers and terpolymers, as shown in Figure 7.

As the comonomer content is increased, differences between the three polymer families increase, and the melting temperature for ethylene copolymers and terpolymers moves to lower values. This is also observed in other $\alpha$-olefin copolymers, where it has been noted that thermal transition differences are emphasized as the lateral chain increases [46].

Focusing the attention in the $\mathrm{S}$ samples, their melting curves present a well clear bimodal behavior (see Figure 6, right) with a shoulder at around $130{ }^{\circ} \mathrm{C}$ corresponding, most probably, to the melting of the $\gamma$ form crystals, and a main peak around $150{ }^{\circ} \mathrm{C}$ corresponding to the $\alpha$ form. That shoulder is practically absent for the homopolymer, where the $\gamma$ content is rather small.

The relative intensities of the two endotherms in the $\mathrm{S}$ specimens reflect somehow the ratio of $\gamma$ and $\alpha$ crystals initially present in the sample, although now the deconvolution for determining the relative proportion of them is much more difficult than in the case of X-ray diffraction.

Polypropylene produced with a Ziegler Natta catalyst has a broad distribution of defects from chain to chain and a distribution of defects intramolecularly that deviates strongly from the random behavior: the defects are more concentrated in the molecules with lower molar mass [36]. Since the presence of short isotactic sequences is a requirement for the formation of the $\gamma$ polymorph, it is not surprising that $\mathrm{ZN}$ iPP homopolymer leads to insignificant contents of crystallites of the $\gamma$ form, contrary to the case of iPP synthesized with a metallocene catalyst with the same overall concentration of defects.

The type and proportion of monomer are also crucial for the transition associated with the amorphous component, the glass transition, as shown in Figure 8, which represents the glass transition variation for the samples with thermal treatment $\mathrm{Q}$. The values found for the 
copolymers with ethylene are significantly lower than those for 1-butene as comonomer, reflecting mainly the much lower glass transition temperature of polyethylene homopolymer in relation to poly-1-butene $[47,48]$.

\subsection{Mechanodynamical properties}

Mechanodynamical studies have been performed on the samples, using several frequencies. For comparison between the different types of polymers, the $3 \mathrm{~Hz}$ frequency curves have been used, as shown in Figure 9, Figure 10 and Figure 11.

As usual in iPP samples, several relaxations can be observed. The $\alpha$ relaxation (in the high temperature region) is associated with movements within the crystals and is affected not only by the overall crystallinity but also by the crystal size and distribution. If there is less ability for movements in the crystalline phase, this relaxation will increase its activation energy. This would be the case when crystallinity increases or when there is a wide crystal size distribution due to crystal imperfection.

When increasing comonomer content and thus decreasing the crystallinity, this relaxation corresponding to the crystalline phase appears at lower temperatures for each type of copolymer studied.

As for the type of comonomer, 1-butene copolymers show higher temperatures for the $\alpha$-relaxation with respect to ethylene copolymers and terpolymers, due to their higher crystallinity and crystal size, which produces a movement restriction.

Furthermore, the intensity decreases and the relaxation peak position shifts to higher temperatures as the cooling speed from the melt is slowed in a certain copolymer, as seen by comparing the samples with $\mathrm{Q}$ and $\mathrm{S}$ thermal treatment. The intensity decrease is due to the crystal size distribution, narrower in S samples which have been cooled more slowly, and the crystals have had longer time to grow homogeneously. Additionally, there are two crystalline forms (monoclinic and orthorhombic) in the samples $\mathrm{S}$, and possible differences in the relaxation mode of the two types of crystals could also influence the intensity.

The $\beta$ relaxation is associated with the glass transition temperature and appears when mobility of the amorphous regions of the polymer starts. Its intensity is, therefore, inversely proportional to crystallinity, so that the homopolymer shows a less intense and narrower $\beta$ relaxation than copolymers and terpolymers. Moreover, terpolymers present the most intense $\beta$-relaxation, in particular in the terpolymer PRE4.2B5.6, since this is the material showing the lowest crystallinity. Ethylene and 1-butene copolymers show lower intensity and similar 
behavior among them. Its maximum is shifted to higher temperatures in the case of copolymers of 1-butene, feature that is associated with a greater crystallinity, resulting in decreased content of amorphous phase. The homopolymer Tg value, which is obtained from $\beta$ relaxation, is very close to that of copolymers with low comonomer content, and considerably higher than the Tg value obtained from calorimetric measurements, as usual. ${ }^{[49]}$.

The $\gamma^{\mathrm{CH} 3}$ relaxation occurs at temperatures within the range -65 to $-30{ }^{\circ} \mathrm{C}$, below the glass transition. Its intensity is lower than the $\beta$ relaxation and it is associated with movements of polypropylene methyl groups. This relaxation is very little visible in copolymers and terpolymers studied in this work, and also has a very low intensity in 1hexene and 1-octadecene copolymers reported by Palza et al., probably due to the fact that the incorporation of a comonomer into the polypropylene chain leads to a reduced steric hindrance between methyl groups. ${ }^{[50]}$

At low temperatures, the presence of a relaxation, named as $\gamma^{\prime}$, is observed in the temperature range of -130 to $-120{ }^{\circ} \mathrm{C}$. This relaxation is especially noticeable in the case of copolymers of 1-butene, whereas the ethylene is the one with less intensity. Therefore it would be associated with the $\mathrm{CH}_{2}-\mathrm{CH}_{3}$ branch formed by the introduction of 1-butene comonomer. This relaxation has also been observed in isotactic polypropylene copolymers ${ }^{[51]}$ and on syndiotactic polypropylene ${ }^{[52]}$ copolymers with long chain $\alpha$-olefin, also named $\gamma^{\mathrm{CH} 2}$ and appears to have the same molecular causes than polyethylene $\gamma$ relaxation: crank type movements in methylene groups. ${ }^{[53-54]}$ This $\gamma^{\mathrm{CH} 2}$ relaxation appears in 1-hexene copolymers only at high comonomer contents, exceeding $8 \mathrm{~mol} \%$, while in this work it is observed in copolymers of 1-butene above around $5 \mathrm{~mol} \%$ of comonomer incorporation. However, it is noteworthy that the copolymers of 1-hexene reported in the literature are produced with metallocene catalyst, which affects the distribution of comonomer in the chain.

The comparison between the different types of polymers studied allows us to note that copolymers with the highest comonomer incorporation have a loss modulus $E^{\prime}$ lower than homopolymer and copolymers with lower incorporation. As the temperature rises, the partial mobility is increased, and a gradual decrease of the storage modulus is observed.

\subsection{Mechanical properties}

Stress-strain and microhardness measurements have been performed on the different samples. Table 5 lists different mechanical parameters for the specimens under both $\mathrm{Q}$ as $\mathrm{S}$ thermal treatments. It is deduced from the values of tensile modulus and tensile stress at yield 
that the incorporation of comonomer reduces the stiffness of the sample, as it disturbs the crystal structure. The decrease in stiffness is more prominent in ethylene than in 1-butene copolymers. By contrast, 1-butene copolymers show lower elongation values. These trends are more pronounced in the case of S samples.

On the other hand, microhardness variation with type of comonomer and thermal treatment is also detailed in Table 5. Again the presence of counits is reflected on lower values of $\mathrm{MH}$, this trend being again much more evident in the S-cooled samples. Anyway, the values of $\mathrm{MH}$ display a relative variation which is rather similar to that of the Young modulus. ${ }^{[45]}$

\subsection{Optical properties}

Polypropylene is a semi-crystalline polymer whose transparency is closely related to the details of its structure. Thus, the development of crystalline superstructures larger than the wavelength of visible light $(400-700 \mathrm{~nm})$, results in interference phenomena and light scattering through the polymer, which determines the resulting optical properties.

Three kinds of optical properties have been determined on the present samples: clarity, overall visible light transmission (TGLV) and haze. The corresponding values are shown in Table 6, for the Q specimens.

It can be observed that the TGLV and the clarity of the terpolymers are superior to both copolymers of ethylene and 1-butene. The introduction of two types of comonomer in the structure produces a greater degree of imperfection, which leads to a morphology richer in $\gamma$ crystal structures and slightly lower overall crystallinity. All this affects the transparency, making terpolymers very attractive for applications such as transparent film or packaging, products with high aesthetic requirements. As deduced from Figure 12, the values of clarity for the terpolymers are higher than $90 \%$ for comonomer contents above around 3-4 mol\%.

By contrast, copolymers of 1-butene are those with less clarity and overall transmission of light. Butene unit becomes part of the crystalline structure in greater proportion than ethylene, the overall crystallinity is higher and has lower proportion of $\gamma$ morphology, hence its optical properties are slightly lower than those of ethylene copolymers and terpolymers. Regarding the comonomer content, clarity is enhanced and haze reduced as the comonomer concentration increases. 


\section{Conclusions}

A set of Ziegler-Natta copolymers of iPP with ethylene or with 1-butene, and terpolymers with both counits has been characterized. Since 1-butene comonomer, due to its structural similarity with propylene, is introduced into the crystal lattice of iPP to a higher extent that ethylene, thus 1-butene copolymers show greater crystallinity, for a composition of the same order, with respect to ethylene copolymers and terpolymers, and display the highest crystallization temperature values.

Terpolymers present the lowest crystallinity, melting temperatures and crystallization temperatures, since both types of comonomers produce a higher distortion of the crystal structure. In addition, terpolymers show broader endotherms, revealing a widest crystal size distribution and exhibit the highest proportion of $\gamma$-form. The presence of two different types of comonomers induces the shortening of the crystallizable sequence and thus favors formation of $\gamma$-crystals.

DMTA analysis show a displacement of the $\alpha$-relaxation, corresponding to the crystalline phase, to lower temperatures together with a decrease in the intensity as the comonomer content is increased. 1-Butene copolymers lead to higher temperatures, with respect to ethylene copolymers and terpolymers, due to their higher crystallinity and crystal size, which produces a movement restriction. At low temperatures, the presence of a relaxation, named as $\gamma^{\prime}$, is observed in the temperature range of -130 to $-120{ }^{\circ} \mathrm{C}$. This relaxation is especially noticeable in the case of copolymers of 1-butene, whereas the ethylene is the one with less intensity.

These structural differences have a great influence on the mechanical and optical properties. Thus, 1-butene copolymers present higher values of elastic modulus, tensile strength and microhardness, penalizing its transparency. These features make them suitable for injection molding applications, where a balance of mechanical and optical properties is desired, as well as film applications needing a commitment between tensile strength, transparency and low sealing temperature.

Terpolymers exhibit higher transparency than ethylene and 1-butene copolymers, at the same overall comonomer content. Their mechanical properties, on the other hand, are penalized, showing elastic modulus and tensile strength lower than copolymers. These features make terpolymers excellent products for film packaging applications. In addition to presenting very good optical properties, they have a crystalline structure full of imperfections that leads to wide melting curves, an important advantage in the sealing of the film that can be 
done at lower temperature, thus increasing the speed of the production process.

Acknowledgments: The financial support of MICINN (projects CYTED 311RT0417 and MAT2013-47972-C2-1-P), is gratefully acknowledged. 


\section{References}

[1] S. Brückner, S.V. Meille,V. Petraccone, B. Pirozzi, Polymorphism in isotactic polypropylene, Prog. Polym. Sci. 16 (1991) 361-404.

[2] B. Lotz, J.C. Wittmann, A.J. Lovinger, Structure and morphology of poly(propylenes): a molecular analysis, Polymer 3 (1996) 4979-4992.

[3] J. Varga, Supermolecular structure of isotactic polypropylene, J. Mater. Sci. 27 (1992) 2557-2579.

[4] P.J. Phillips, K. Mezghani, In the Polymeric Materials Encyclopedia; Salamone, J. C., Ed.; CRC Press: Boca Raton, FL, 1996; Vol. 9, p 6637.

[5] B. Poon, M. Rogunova, A. Hiltner, E. Baer, S.P. Chum, A. Galeski, E. Piorkowska, Structure and Properties of Homogeneous Copolymers of Propylene and 1-Hexene, Macromolecules 38 (2005) 1232-1243.

[6] B. Lotz, J. Ruan, A. Thierry, G.C. Alfonso, A. Hiltner, E. Baer, E. Piorkowska, A. Galeski, Macromolecules 39 (2006) 5777-5781.

[7] C. De Rosa, S. Dello Iacono, F. Auriemma, E. Ciaccia, L. Resconi, Crystal Structure of Isotactic Propylene-Hexene Copolymers: The Trigonal Form of Isotactic Polypropylene, Macromolecules 39 (2006) 6098-6109.

[8] M.L. Cerrada, M.J. Polo-Corpa, R. Benavente, E. Pérez, T. Velilla, R. Quijada, Formation of the New Trigonal Polymorph in iPP-1-Hexene Copolymers. Competition with the Mesomorphic Phase, Macromolecules 42 (2009) 702-708.

[9] E. Pérez, M.L. Cerrada, R. Benavente, J.M. López-Elvira, Enhancing the Formation of the New Trigonal Polymorph in Isotactic Propene-1-Pentene Copolymers: Determination of the X-ray Crystallinity, Macromol. Res. 19 (2011) 1179-1185.

[10] A. García-Peñas, J.M. Gómez-Elvira, E. Pérez, M.L. Cerrada, Isotactic Poly(propyleneco-1-pentene-co-1-hexene) Terpolymers: Synthesis, Molecular Characterization, and Evidence of the Trigonal Polymorph, J. Polym. Sci. Part A: Polym. Chem. 51 (2013) 32513259.

[11] D. Mileva, D. Cavallo, L. Gardella, G.C. Alfonso, G. Portale, L. Balzano, R. Androsch, In situ X-ray analysis of mesophase formation in random copolymers of propylene and 1butene, Polym. Bull. 67 (2011) 497-510.

[12] E. Pérez, J. M. Gómez-Elvira, R. Benavente, and M. L. Cerrada, Tailoring the Formation Rate of the Mesophase in Random Propylene-co-1-pentene Copolymers, Macromolecules 45 (2012) 6481-6490. 
[13] M.J. Polo-Corpa, R. Benavente, T. Velilla, R. Quijada, E. Pérez, M.L. Cerrada, Development of the mesomorphic phase in isotactic propene/higher a-olefin copolymers at intermediate comonomer content and its effect on properties, Eur. Polym. J.46 (2010) 13451354.

[14] J. Arranz-Andrés, R. Parrilla, M. L. Cerrada and E. Pérez, Mesophase Formation in Random Propylene-co-1-octene Copolymers, Macromolecules 46 (2013) 8557-8568.

[15] G. Guidetti; P. Busi; I. Giulianelli; R. Zanetti, Structure-properties relationships in some random copolymers of propylene, Eur. Polym. J. 19 (1983) 757-759.

[16] A. Marigo, C. Marega, R. Saini, I. Camurati, Influence of Regioirregular Structural Units on the Crystallization of Isotactic Polypropylene, J. Appl. Polym. Sci.79 (2001) 375-384.

[17] S. Laihonen, U.W. Gedde, P.E. Werner, J. Martínez-Salazar, Crystallization kinetics and morphology of poly(propylene-stat-ethylene) fractions, Polymer, 38 (1997) 361-369.

[18] K. Mezghani, P.J. Philips, The $\gamma$-phase of high molecular weight isotactic polypropylene: III. The equilibrium melting point and the phase diagram, Polymer 39 (1998) 3735-3744.

[19] J. Arranz-Andrés, I. Suárez, R. Benavente, E. Pérez, Characterization and Properties of Ethylene-Propylene Copolymers Synthesized with Homogeneous and Supported Metallocene Catalyst in the Whole Range of Compositions, Macromol. Res. 19 (2011) 351-363.

[20] C. De Rosa; F. Auriemma; O. Ruiz de Ballesteros; L. Resconi; I. Camurati, Crystallization Behavior of Isotactic Propylene-Ethylene and Propylene-Butene Copolymers: Effect of Comonomers versus Stereodefects on Crystallization Properties of Isotactic Polypropylene, Macromolecules 40 (2007) 6600-6616.

[21] K. Jeon, Y.L. Chiari, R.G. Alamo, Maximum Rate of Crystallization and Morphology of Random Propylene Ethylene Copolymers as a Function of Comonomer Content up to $21 \mathrm{~mol}$ $\%$, Macromolecules, 41 (2008) 95-108.

[22] R. Benavente, J.M. Pereña, A. Bello, E. Pérez, P. Locatelli, Z. Fan, D. Zucchi, Thermal and viscoelastic behaviour of copolymers of propene and 1-hexene, Polym. Bull. 36 (1996) 249-256.

[23] G. Barrera Galland, F.F. Nunes Escher, L. Forgiarini da Silva, M.M. de Camargo Forte, R. Quijada, Ethylene-Propylene-a-Olefin Terpolymers Thermal and Mechanical Properties, J. Appl. Polym. Sci. 104 (2007) 3827.

[24] A. García-Peñas, J.M. Gómez-Elvira, E. Pérez, M.L. Cerrada, Microstructure of Metallocene Isotactic Propylene-co-1-Pentene-co-1-Hexene Terpolymers, J. Polym. Sci. Part A: Polym. Chem. 52 (2014) 2537-2547. 
[25] F.F. Nunes Escher, G. Barrera Galland, ${ }^{13}$ Carbon Nuclear Magnetic Resonance of Ethylene-Propylene-1-hexene Terpolymers, J. Polym. Sci. Part A: Polym. Chem. 42 (2004) 2474-2482.

[26] F.F. Nunes Escher, G. Barrera Galland, M. Ferreira, ${ }^{13}$ Carbon Nuclear Magnetic Resonance of Ethylene-Propylene-1-Decene Terpolymers, J. Polym. Sci. Part A: Polym. Chem. 41 (2003) 2531-2541.

[27] .E.B. Bond, J.E. Spruiell, J.S. Lin, A WAXD/SAXS/DSC Study on the Melting Behavior of Ziegler-Natta and Metallocene Catalyzed Isotactic Polypropylene, J. Polym. Sci., Part B:

Polym. Phys. 37 (1999) 3050-3064.

[28] R. Krache, R. Benavente, J. M. López-Majada, J. M. Pereña, M.L. Cerrada, E. Pérez, Competition between $\alpha, \beta$, and $\gamma$ Polymorphs in a $\beta$-Nucleated Metallocenic Isotactic Polypropylene, Macromolecules 40 (2007) 6871-6878.

[29] O. Prieto; J.M. Pereña, R. Benavente, M.L Cerrada, E. Pérez, Effect of Composition and Molecular Weight on the Crystallization Behavior of Blends of iPP and a Metallocenic Ethylene/1-Octene Copolymer, Macromol. Chem. Phys. 203 (2002) 1844-1851.

[30] S. Mansel, E. Pérez, R. Benavente, J.M. Pereña, A. Bello, W. Roll, R. Kirsten, S. Beck, $\mathrm{H}-\mathrm{H}$. Brintzinger, Synthesis and properties of elastomeric poly(propylene), Macromol. Chem. Phys. 200 (1999) 1292-1297.

[31] A. Turner-Jones, J.M. Aizlewood, D.R Beckett, Crystalline forms of isotactic polypropylene, Macromol. Chem. Phys. 75 (1964) 134-158.

[32] F.J. Baltá Calleja, Microhardness relating to crystalline polymers, Adv. Polym. Sci. 66 (1985) 117-148.

[33] A. Alizadeh, L. Richardson, J. Xu, S. McCartney, H. Marand, Y.W. Cheung, S. Chum, Influence of Structural and Topological Constraints on the Crystallization and Melting Behavior of Polymers. 1. Ethylene/1-Octene Copolymers, Macromolecules 32 (1999) 62216235.

[34] Z. Mencik, Crystal Structure of Isotactic Polypropylene, J. Macromol. Sci. Part B, Pol. Phys. 101 (1972) 101-115.

[35] S.V. Meille, D.R. Ferro, S. Brückner, Recent results on the polymorphic behavior of isotactic polypropylene, Macromol. Symp. 89 (1995) 499-511.

[36] I.L. Hosier, R.G. Alamo, P. Esteso, J.R. Isasi, L. Mandelkern, Formation of the $\alpha$ and $\gamma$ Polymorphs in Random Metallocene-Propylene Copolymers. Effect of Concentration and Type of Comonomer, Macromolecules 36 (2003) 5623-5636. 
[37] B. Monasse, J.M. Haudin, Effect of random copolymerization on growth transition and morphology change in polypropylene, Colloid Polym. Sci. 266 (1998) 679-687.

[38] P. Cavallo, E. Martuscelli, M. Pracella, Effect of thermal treatment on solution grown crystals of isotactic propylene/butene-1 copolymers, Polymer 18 (1977) 891-896.

[39] C. Ruiz-Orta, R. G. Alamo, Morphological and kinetic partitioning of comonomer in random propylene 1-butene copolymers, Polymer 53 (2012) 810-822.

[40] K. Jeon, H. Palza, R. Quijada, R.G. Alamo, Effect of comonomer type on the crystallization kinetics and crystalline structure of random isotactic propylene 1-alkene copolymers, Polymer 50 (2009) 832-844.

[41] Y. Feng, J.N. Hay, The characterisation of random propylene-ethylene copolymer, Polymer 39 (1998) 6589-6596.

[42] S. Hosoda, H. Hori, K. Yada, S. Nakahara, M. Tsuji, Degree of comonomer inclusion into lamella crystal for propylene/olefin copolymers, Polymer 43 (2002) 7451-7460.

[43] L. E. Alexander. X-ray Diffraction Methods in Polymer Science. Ed. Wiley-Interscience, New York, 1969.

[44] C. Nakafuku, High pressure d.t.a. study on the melting and crystallization of isotactic polypropylene, Polymer 22 (1981) 1673-1676.

[45] J.M. López-Majada, H. Palza, J.L. Guevara, R. Quijada, M.C. Martínez, R. Benavente, J.M. Pereña, E. Pérez, M.L. Cerrada, Metallocene Copolymers of Propene and 1-Hexene: The Influence of the Comonomer Content and Thermal History on the Structure and Mechanical Properties, J. Polym. Sci. Polym. Phys. 44 (2006) 1253-1267.

[46] J.M. López-Majada, Modificación química y física de polipropileno metalocénico, Tesis doctoral. Universidad del País Vasco 2008, Spain.

[47] I. A. Volegova, E.V. Konyukhova, Yu.K. Godovsky, Dynamic mechanical characterization of molecular motion in a wide temperature range of various polymers containing propylene units, J. Thermal. Anal. Calorim. 59 (2000) 123-130.

[48] J.N. Fowler, B.R. Chapman, D.L. Green, Impact of plasticizers and tackifiers on the crystallization of isotactic poly(1-butene), Eur. Polym. J. 46 (2010) 568-577.

[49] E. Pérez, Z. Zhen, A. Bello, R. Benavente, J.M. Pereña, Phase transitions in liquid crystalline poly(octamethylene p,p'-dibenzoate), Polymer 35 (1994) 4794-4798.

[50] H. Palza, J.M. López-Majada, R. Quijada, R. Benavente, E. Pérez, M.L. Cerrada, Metallocenic Copolymers of Isotactic Propylene and 1-Octadecene: Crystalline Structure and Mechanical Behavior, Macromol. Chem. Phys. 206 (2005) 1221-1230. 
[51] H. Palza, J.M. López-Majada, R. Quijada, J.M. Pereña, R. Benavente, E. Pérez, M.L. Cerrada. Comonomer Length Influence on the Structure and Mechanical Response of Metallocenic Polypropylenic Materials, Macromol. Chem. Phys. 209 (2008) 2259-2267.

[52] J. Arranz-Andrés, J.L. Guevara, T. Velilla, R. Quijada, R. Benavente, E. Pérez, M.L. Cerrada, Syndiotactic polypropylene and its copolymers with alpha-olefins. Effect of composition and length of comonomer, Polymer 46 (2005) 12287-12297.

[53] R. H. Boyd, R. S. Breitling, The Conformational Analysis of Crankshaft Motions in Polyethylene, Macromolecules 7 (1974) 855-862.

[54] N. J. Heaton, R. Benavente, E. Pérez, A. Bello, J. M. Pereña, The $\gamma$ relaxation in polymers containing ether linkages: conformational dynamics in the amorphous phase for a series of polybibenzoates containing oxyethylene spacers, Polymer 37 (1996) 3791-3798. 
Table 1. Characteristics of the Ziegler-Natta iPP samples studied.

\begin{tabular}{|l|c|c|c|c|c|}
\hline \multirow{2}{*}{ Sample } & \multicolumn{2}{|c|}{ comonomer content $(\mathrm{mol} \%)$} & \multirow{2}{*}{$\begin{array}{c}\mathrm{M}_{\mathrm{w}} \\
(\mathrm{g} / \mathrm{mol})\end{array}$} & $\begin{array}{c}\mathrm{M}_{\mathrm{n}} \\
(\mathrm{g} / \mathrm{mol})\end{array}$ & PI \\
\cline { 2 - 6 } HOMO & 0 & 0 & 544000 & 82000 & 6.6 \\
\hline PRE2.5 & 2.5 & 0 & 323000 & 90000 & 3.6 \\
\hline PRE4.8 & 4.8 & 0 & 385000 & 88000 & 4.4 \\
\hline PRE8.9 & 8.9 & 0 & 617000 & 125000 & 5.0 \\
\hline PRB1.6 & 0 & 1.6 & 717000 & 140000 & 5.3 \\
\hline PRB5.0 & 0 & 5.0 & 523000 & 122000 & 4.3 \\
\hline PRB8.8 & 0 & 8.8 & 630000 & 147000 & 4.3 \\
\hline PRE1.0B1.0 & 1.0 & 1.0 & 262000 & 89000 & 2.9 \\
\hline PRE1.5B3.0 & 1.5 & 3.0 & 250000 & 59000 & 4.2 \\
\hline PRE4.2B5.6 & 4.2 & 5.6 & 638000 & 173000 & 3.7 \\
\hline
\end{tabular}


Table 2. Diffraction angles for samples with $\mathrm{Q}$ and $\mathrm{S}$ treatment.

\begin{tabular}{|l|c|c|c|c|c|c|c|c|c|c|c|c|}
\hline Reflection & $\mathbf{( 1 1 1 )}$ & $\mathbf{( 1 1 0})$ & $\mathbf{( 1 1 3})$ & $\mathbf{( 0 0 8 )}$ & $\mathbf{( 0 4 0 )}$ & $\mathbf{( 1 3 0 )}$ & $\mathbf{( 1 1 7})$ & $\mathbf{( 1 1 1})$ & $\mathbf{( 2 0 2})$ & $\mathbf{( 1 3 1 )}$ & $\mathbf{( 0 2 6 )}$ & $\mathbf{( 0 6 0 )}$ \\
\hline $2 \theta$ & 13.9 & 14.1 & 15.0 & 16.5 & 16.5 & 18.7 & 20.1 & 21.1 & 21.2 & 21.8 & 21.9 & 25.8 \\
\hline Morphology & $\gamma$ & $\alpha$ & $\gamma$ & $\gamma$ & $\alpha$ & $\alpha$ & $\gamma$ & $\alpha$ & $\gamma$ & $\alpha$ & $\gamma$ & $\alpha$ \\
\hline HOMO-Q & & 14.2 & & & 17.0 & 18.6 & & 21.2 & & 22.0 & & 25.5 \\
\hline PRE2.5-Q & 14.2 & & & 17.0 & 18.6 & & 21.2 & & 22.0 & & 25.6 \\
\hline PRE4.8-Q & 14.2 & & & 17.0 & 18.6 & & 21.3 & & 22.0 & & 25.6 \\
\hline PRE8.9-Q & 14.2 & & & 17.0 & 18.6 & & 21.3 & & 21.9 & & 25.6 \\
\hline PRB1.6-Q & 14.2 & & & 16.9 & 18.6 & & 21.2 & & 21.9 & & 25.4 \\
\hline PRB5.0-Q & 14.1 & & & 16.7 & 18.4 & & 21.1 & & 21.7 & & 25.3 \\
\hline PRB8.8-Q & 14.1 & & & 16.7 & 18.4 & & 21.1 & & 21.7 & & 25.1 \\
\hline PRE1.0B1.0-Q & 14.2 & & & 17.0 & 18.6 & & 21.3 & & 22.0 & & 25.5 \\
\hline PRE1.5B3.0-Q & & 14.1 & & & 16.8 & 18.5 & & 21.3 & & 21.8 & & 25.3 \\
\hline PRE4.2B5.6-Q & 14.1 & & & 16.7 & 18.4 & & 21.2 & & 21.6 & & 25.2 \\
\hline & & & & & & & & & & & & \\
\hline HOMO-S & - & 14.2 & & - & 17.0 & 18.7 & - & 21.2 & - & 22.0 & - & 25.6 \\
\hline PRE2.5-S & 14.2 & & 16.9 & 18.7 & 20.1 & 21.3 & 22.0 & 25.5 \\
\hline PRE4.8-S & 14.2 & & 16.9 & 18.7 & 20.2 & 21.3 & 22.0 & 25.5 \\
\hline PRE8.9-S & 14.2 & & 16.9 & 18.7 & 20.2 & 21.3 & 22.0 & 25.5 \\
\hline PRB1.6-S & 14.2 & & 16.9 & 18.6 & 20.0 & 21.2 & 21.9 & 25.4 \\
\hline PRB5.0-S & 14.1 & & 16.8 & 18.6 & 20.1 & 21.2 & 21.9 & 25.4 \\
\hline PRB8.8-S & 14.1 & & 16.7 & 18.5 & 19.9 & 21.1 & 21.9 & 25.3 \\
\hline PRE1.0B1.0-S & 14.2 & & 16.9 & 18.7 & 20.1 & 21.3 & 22.0 & 25.4 \\
\hline PRE1.5B3.0-S & 14.2 & & 16.8 & 18.6 & 20.1 & 21.2 & 21.9 & 25.2 \\
\hline PRE4.2B5.6-S & 14.2 & & 16.7 & 18.6 & 20.0 & 21.2 & 21.9 & 25.0 \\
\hline
\end{tabular}


Table 3. X-ray diffraction results: degree of crystallinity (total and for each modification $\alpha$ and $\gamma$ ), and crystal size lc(110) for the samples under the two thermal treatments.

\begin{tabular}{|l|c|c|c|c|c|c|c|}
\hline & \multicolumn{5}{|c|}{ Q } & \multicolumn{3}{c|}{ S } \\
\hline Sample & $\mathrm{f}_{\mathrm{c} \text { total }}$ & $\mathrm{f}_{\alpha}$ & $\mathrm{f}_{\gamma}$ & $\mathrm{l}_{\mathrm{c}}(110)(\mathrm{nm})$ & $\mathrm{f}_{\mathrm{c} \text { total }}$ & $\mathrm{f}_{\alpha}$ & $\mathrm{f}_{\gamma}$ \\
\hline HOMO & 0.55 & 0.55 & 0.00 & 22.2 & 0.61 & 0.56 & 0.05 \\
\hline PRE2.5 & 0.56 & 0.56 & 0.00 & 20.2 & 0.62 & 0.39 & 0.23 \\
\hline PRE4.8 & 0.55 & 0.53 & 0.02 & 19.6 & 0.56 & 0.27 & 0.29 \\
\hline PRE8.9 & 0.48 & 0.47 & 0.01 & 18.4 & 0.51 & 0.13 & 0.38 \\
\hline PRB1.6 & 0.54 & 0.54 & 0.00 & 20.8 & 0.60 & 0.48 & 0.12 \\
\hline PRB5.0 & 0.54 & 0.54 & 0.00 & 18.4 & 0.59 & 0.35 & 0.24 \\
\hline PRB8.8 & 0.48 & 0.48 & 0.00 & 18.3 & 0.53 & 0.28 & 0.25 \\
\hline PRE1.0B1.0 & 0.56 & 0.56 & 0.00 & 20.3 & 0.61 & 0.38 & 0.23 \\
\hline PRE1.5B3.0 & 0.53 & 0.52 & 0.01 & 19.2 & 0.56 & 0.23 & 0.33 \\
\hline PRE4.2B5.6 & 0.47 & 0.46 & 0.01 & 18.2 & 0.52 & 0.13 & 0.39 \\
\hline
\end{tabular}


Table 4. Total enthalpy of melting, DSC degree of crystallinity, melting temperature of the two polymorphs and glass transition temperature, for the different samples under the Q and $\mathrm{S}$ thermal treatment.

\begin{tabular}{|c|c|c|c|c|c|}
\hline Sample & $\Delta \mathbf{H}_{\mathrm{m}}(\mathbf{J} / \mathbf{g})$ & $\mathbf{f}_{c}{ }^{\mathrm{DSC}}(\%)$ & $\mathbf{T}_{\mathbf{m}}^{\alpha}\left({ }^{0} \mathbf{C}\right)$ & $\mathbf{T}_{\mathbf{m}}^{\gamma}\left({ }^{\mathbf{o}} \mathbf{C}\right)$ & $\mathbf{T}_{\mathrm{g}}\left({ }^{\circ} \mathbf{C}\right)$ \\
\hline HOMO-Q & 100.5 & 0.60 & 158.9 & - & 0.5 \\
\hline PRE2.5-Q & 100.5 & 0.60 & 151.3 & - & -7.7 \\
\hline PRE4.8-Q & 91.9 & 0.55 & 139.1 & - & -8.0 \\
\hline PRE8.9-Q & 81.2 & 0.49 & 127.5 & - & -14.5 \\
\hline PRB1.6-Q & 104.1 & 0.62 & 152.4 & - & 0.1 \\
\hline PRB5.0-Q & 110.8 & 0.57 & 144.1 & - & -2.1 \\
\hline PRB8.8-Q & 107.5 & 0.58 & 136.5 & - & -6.0 \\
\hline PRE1.0B1.0-Q & 97.3 & 0.59 & 148.2 & - & -5.2 \\
\hline PRE1.5B3.0-Q & 91.7 & 0.55 & 135.5 & - & -6.0 \\
\hline PRE4.2B5.6-Q & 68.1 & 0.50 & 120.1 & - & -10.5 \\
\hline HOMO -S & 110.4 & 0.66 & 159.2 & - & -5.0 \\
\hline PRE2.5-S & 109.9 & 0.66 & 154.5 & - & -7.0 \\
\hline PRE4.8-S & 92.8 & 0.56 & 146.2 & 132.1 & -15.5 \\
\hline PRE8.9-S & 84.9 & 0.51 & 136.4 & 120.4 & -19.0 \\
\hline PRB1.6-S & 109.4 & 0.66 & 154.5 & - & -4.9 \\
\hline PRB5.0-S & 105.8 & 0.63 & 150.0 & 130.6 & -8.0 \\
\hline PRB8.8-S & 98.7 & 0.59 & 148.8 & 126.0 & -10.0 \\
\hline PRE1.0B1.0-S & 107.3 & 0.64 & 152.1 & 138.2 & -8.5 \\
\hline PRE1.5B3.0-S & 100.5 & 0.60 & 143.5 & 128.0 & -10.9 \\
\hline PRE4.2B5.6-S & 91.8 & 0.55 & 145.0 & 117.0 & -5.0 \\
\hline
\end{tabular}


Table 5. Stress at break and at yield, strain at break and at yield, Young modulus and Microhardness values for the samples with Q and S thermal treatment.

\begin{tabular}{|l|c|c|c|c|c|c|}
\hline \multicolumn{1}{|c|}{ Sample } & $\sigma_{\mathbf{B}}(\mathbf{M P a})$ & $\sigma_{\mathbf{Y}}(\mathbf{M P a})$ & $\boldsymbol{\varepsilon}_{\mathbf{B}}(\boldsymbol{\%})$ & $\boldsymbol{\varepsilon}_{\mathbf{Y}}(\boldsymbol{\%})$ & $\mathbf{E}(\mathbf{M P a})$ & $\mathbf{M H}(\mathbf{M P a})$ \\
\hline HOMOQ & $40.6 \pm 6.7$ & $27.4 \pm 1.4$ & $905 \pm 125$ & $9.0 \pm 0.4$ & $1199 \pm 162$ & $68 \pm 1$ \\
\hline PRE2.5Q & $41.2 \pm 3.6$ & $24.2 \pm 3.4$ & $892 \pm 43$ & $8.8 \pm 0.3$ & $1043 \pm 88$ & $60 \pm 2$ \\
\hline PRE4.8Q & $42.0 \pm 1.1$ & $19.9 \pm 1.8$ & $910 \pm 12$ & $10.4 \pm 0.4$ & $710 \pm 36$ & $46 \pm 1$ \\
\hline PRE8.9Q & $34.0 \pm 1.6$ & $14.0 \pm 0.5$ & $1009 \pm 39$ & $12.5 \pm 0.6$ & $457 \pm 10$ & $30 \pm 1$ \\
\hline PRB1.6Q & $38.6 \pm 1.5$ & $22.3 \pm 1.1$ & $873 \pm 27$ & $9.3 \pm 0.3$ & $969 \pm 75$ & $65 \pm 2$ \\
\hline PRB5.0Q & $37.9 \pm 5.0$ & $20.5 \pm 0.4$ & $868 \pm 127$ & $8.8 \pm 0.7$ & $895 \pm 34$ & $52 \pm 1$ \\
\hline PRB8.8Q & $40.9 \pm 2.1$ & $18.3 \pm 0.7$ & $885 \pm 33$ & $8.9 \pm 0.4$ & $668 \pm 15$ & $47 \pm 1$ \\
\hline PRE1.0B1.0Q & $41.1 \pm 9.4$ & $23.4 \pm 2.1$ & $875 \pm 146$ & $11.6 \pm 0.7$ & $643 \pm 90$ & $56 \pm 1$ \\
\hline PRE1.5B3.0Q & $42.8 \pm 1.8$ & $21.2 \pm 1.1$ & $877 \pm 10$ & $11.3 \pm 0.4$ & $599 \pm 51$ & $47 \pm 2$ \\
\hline PRE4.2B5.6Q & $39.7 \pm 3.6$ & $16.3 \pm 0.6$ & $877 \pm 49$ & $11.7 \pm 0.3$ & $478 \pm 30$ & $32 \pm 1$ \\
\hline & & & & & & \\
\hline HOMOS & $28.9 \pm 5.0$ & $28.5 \pm 5.5$ & $266 \pm 121$ & $7.6 \pm 0.6$ & $1273 \pm 103$ & $79 \pm 2$ \\
\hline PRE2.5S & $34.1 \pm 3.2$ & $25.1 \pm 0.9$ & $666 \pm 56$ & $8.2 \pm 0.3$ & $1152 \pm 47$ & $79 \pm 2$ \\
\hline PRE4.8S & $38.8 \pm 1.0$ & $19.2 \pm 0.8$ & $867 \pm 25$ & $11.1 \pm 0.1$ & $720 \pm 124$ & $57 \pm 2$ \\
\hline PRE8.9S & $36.9 \pm 3.7$ & $15.5 \pm 1.0$ & $910 \pm 89$ & $13.4 \pm 1.7$ & $509 \pm 47$ & $33 \pm 4$ \\
\hline PRB1.6S & $39.2 \pm 2.5$ & $23.8 \pm 2.8$ & $772 \pm 58$ & $8.0 \pm 1.8$ & $1095 \pm 80$ & $76 \pm 2$ \\
\hline PRB5.0S & $46.2 \pm 9.8$ & $23.5 \pm 3.0$ & $771 \pm 131$ & $10.1 \pm 0.8$ & $913 \pm 42$ & $70 \pm 1$ \\
\hline PRB8.8S & $37.8 \pm 1.2$ & $19.5 \pm 0.9$ & $760 \pm 11$ & $8.6 \pm 0.2$ & $819 \pm 62$ & $63 \pm 1$ \\
\hline PRE1.0B1.0S & $32.4 \pm 6.6$ & $24.1 \pm 1.8$ & $652 \pm 231$ & $9.2 \pm 0.4$ & $1051 \pm 34$ & $70 \pm 2$ \\
\hline PRE1.5B3.0S & $40.9 \pm 7.4$ & $21.4 \pm 0.6$ & $831 \pm 159$ & $11.2 \pm 1.0$ & $872 \pm 25$ & $60 \pm 1$ \\
\hline PRE4.2B5.6S & $40.8 \pm 11.3$ & $16.7 \pm 0.3$ & $802 \pm 247$ & $12.3 \pm 0.6$ & $604 \pm 14$ & $43 \pm 1$ \\
\hline
\end{tabular}


Table 6. Optical properties values for the different samples under Q treatment.

\begin{tabular}{|l|c|c|c|}
\hline Sample & Clarity $(\%)$ & TGLV $(\%)$ & Haze $(\%)$ \\
\hline HOMO & 76.6 & 88.3 & 41.3 \\
\hline PRE2.5 & 73.9 & 88.8 & 38.0 \\
\hline PRE4.8 & 79.8 & 87.0 & 50.9 \\
\hline PRE8.9 & 90.7 & 87.2 & 44.8 \\
\hline PRB1.6 & 37.6 & 88.8 & 66.4 \\
\hline PRB5.0 & 42.4 & 88.3 & 65.0 \\
\hline PRB8.8 & 81.9 & 88.5 & 35.2 \\
\hline PRE1.0B1.0 & 84.3 & 90.0 & 38.4 \\
\hline PRE1.5B3.0 & 92.5 & 90.1 & 33.3 \\
\hline PRE4.2B5.6 & 92.4 & 89.6 & 49.4 \\
\hline
\end{tabular}




\section{LEGENDS FOR THE FIGURES}

Figure 1. a) X-ray diffractograms of the indicated samples, rapidly cooled from the melt, and an example of the amorphous component, amPP; b) Pure crystalline profiles after subtraction of the corresponding amorphous component.

Figure 2. Degree of crystallinity measured by XRD, for Q and S thermal treatments.

Figure 3. Crystal size lc (110) for Q samples (only $\alpha$ crystallization).

Figure 4. Pure crystalline profiles for the samples slowly cooled from the melt.

Figure 5. Variation of $\gamma$ crystallinity with the amount of comonomer for S-samples.

Figure 6. DSC melting curves of the different samples under the Q (left) and S (right) thermal treatment. Heating rate: $20^{\circ} \mathrm{C} / \mathrm{min}$.

Figure 7. Variation of $\mathrm{T}_{\mathrm{m}}$ with comonomer content for 1-butene copolymers, ethylene copolymers and terpolymers.

Figure 8. Variation of $\mathrm{T}_{\mathrm{g}}$ with comonomer content for 1-butene copolymers, ethylene copolymers and terpolymers.

Figure 9. Mechanodynamical curves (at $3 \mathrm{~Hz}$ ) for ethylene copolymers with Q (left) and $\mathrm{S}$ (right) thermal treatment.

Figure 10. Mechanodynamical curves (at $3 \mathrm{~Hz}$ ) for 1-butene copolymers with Q (left) and $\mathrm{S}$ (right) thermal treatment.

Figure 11. Mechanodynamical curves (at $3 \mathrm{~Hz}$ ) for terpolymers with Q (left) and $\mathrm{S}$ (right) thermal treatment.

Figure 12. Variation of clarity with comonomer content for 1-butene copolymers, ethylene copolymers and terpolymers with Q thermal treatment. 


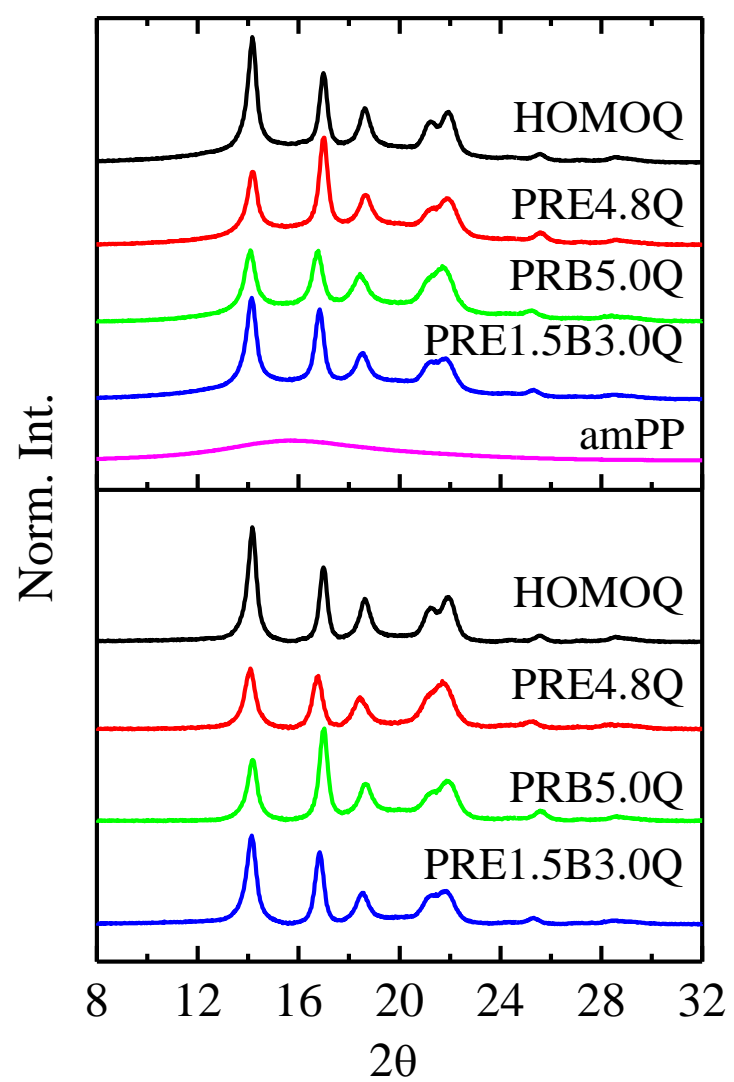

Figure 1. a) X-ray diffractograms of the indicated samples, rapidly cooled from the melt, and an example of the amorphous component, amPP; b) Pure crystalline profiles after subtraction of the corresponding amorphous component. 


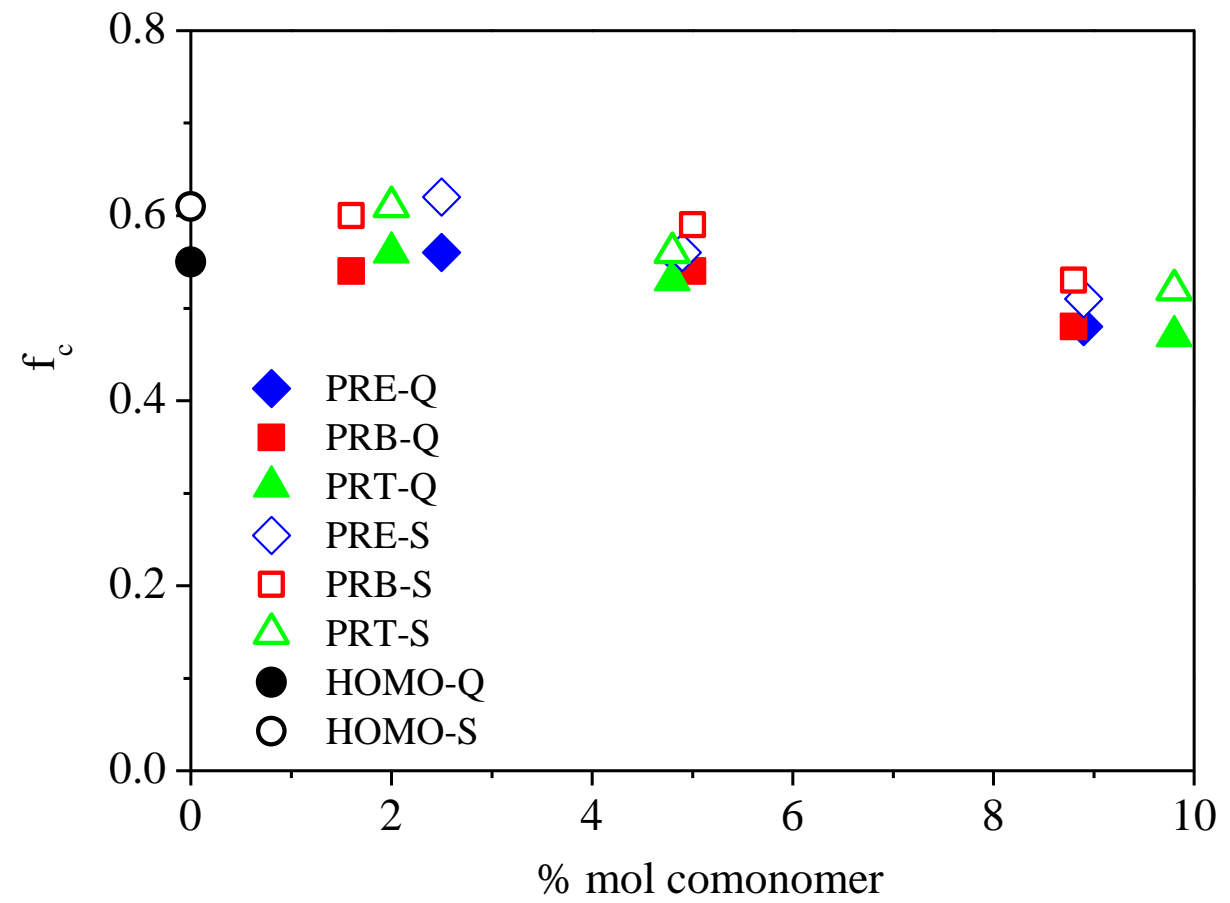

Figure 2. Degree of crystallinity measured by XRD, for Q and S thermal treatments. 


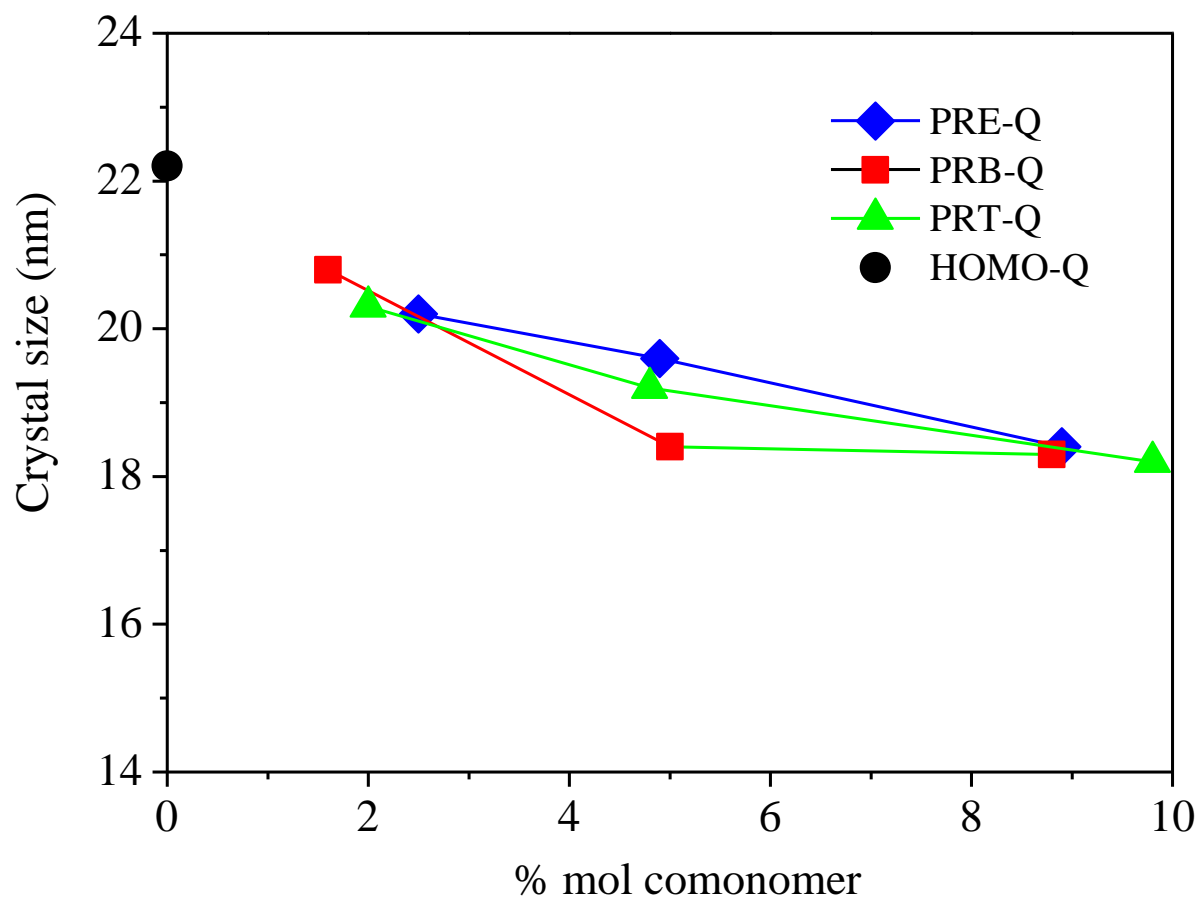

Figure 3. Crystal size lc (110) for Q samples (only $\alpha$ crystallization). 


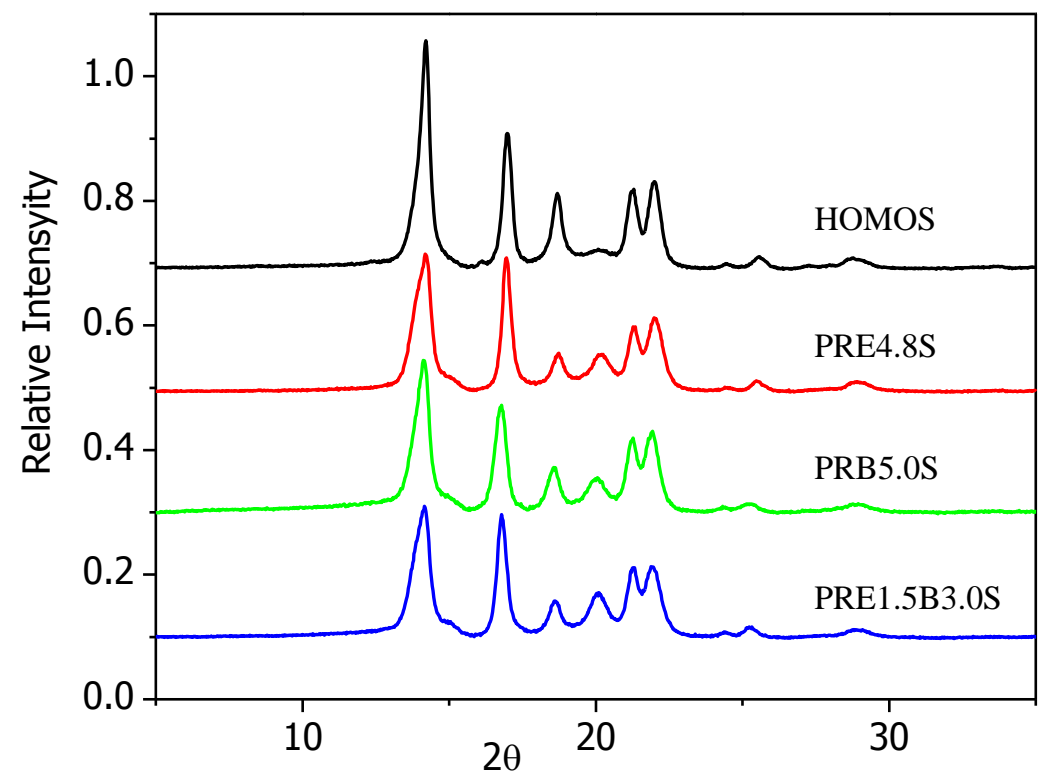

Figure 4. Pure crystalline profiles for the samples slowly cooled from the melt. 


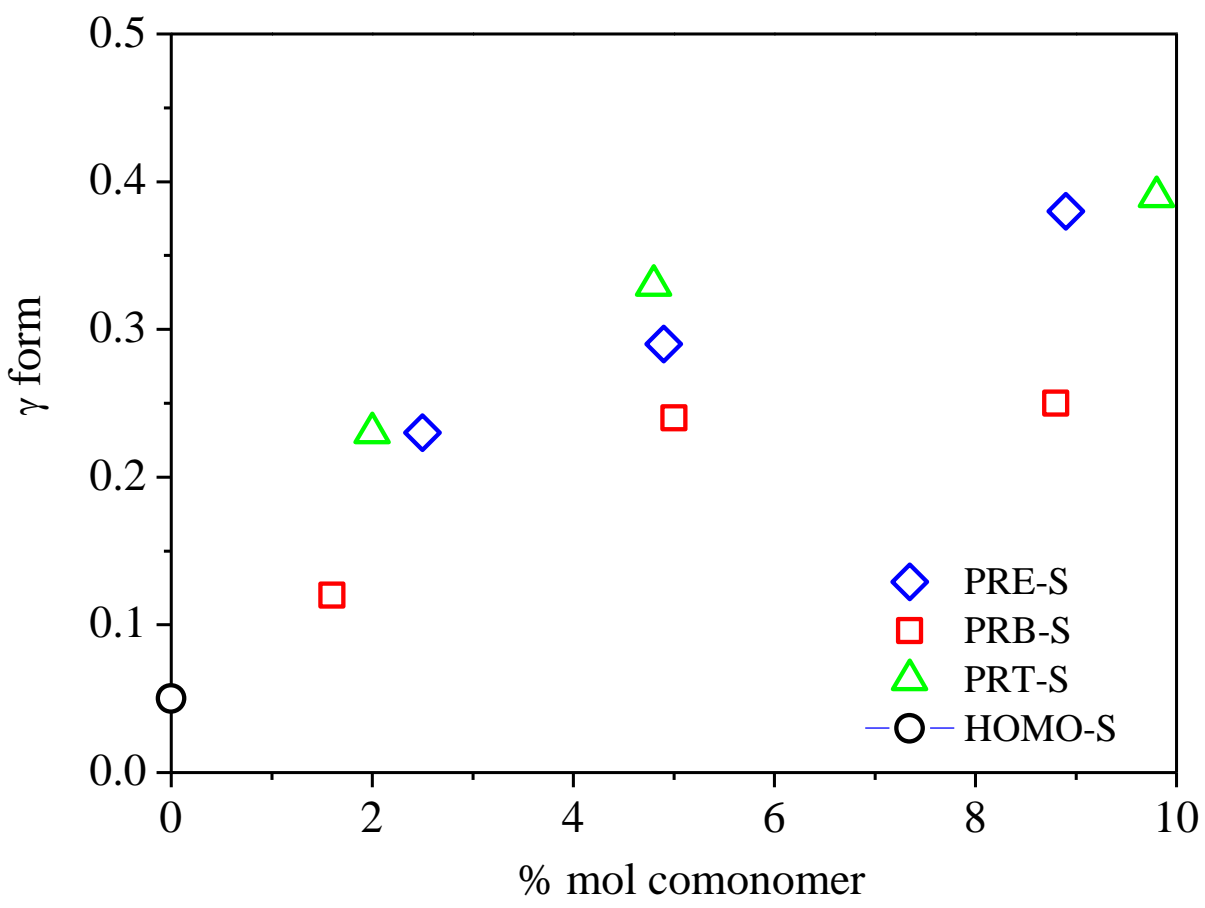

Figure 5. Variation of $\gamma$ crystallinity with the amount of comonomer for S-samples. 

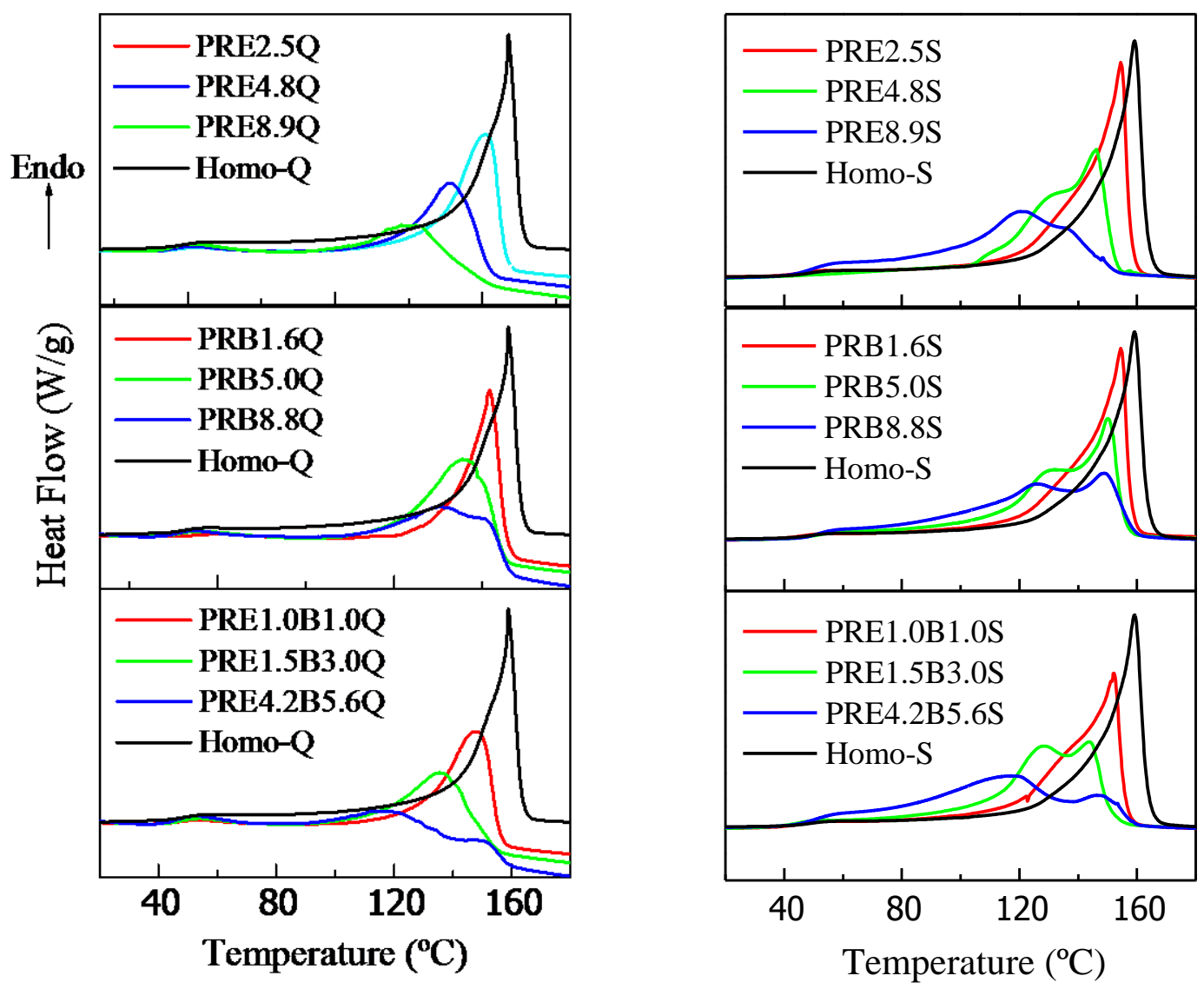

Figure 6. DSC melting curves of the different samples under the Q and S thermal treatment. Heating rate: $20^{\circ} \mathrm{C} / \mathrm{min}$. 


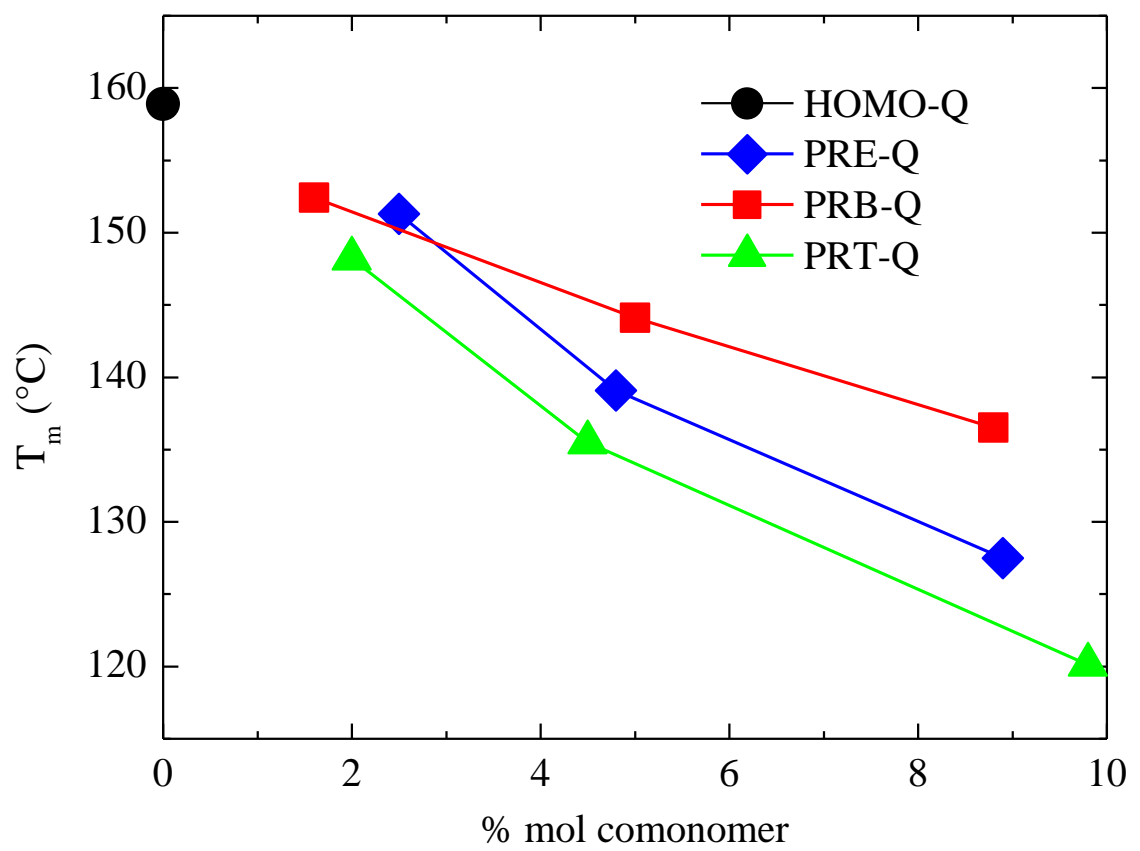

Figure 7. Variation of $T_{m}$ with comonomer content for 1-butene copolymers, ethylene copolymers and terpolymers. 


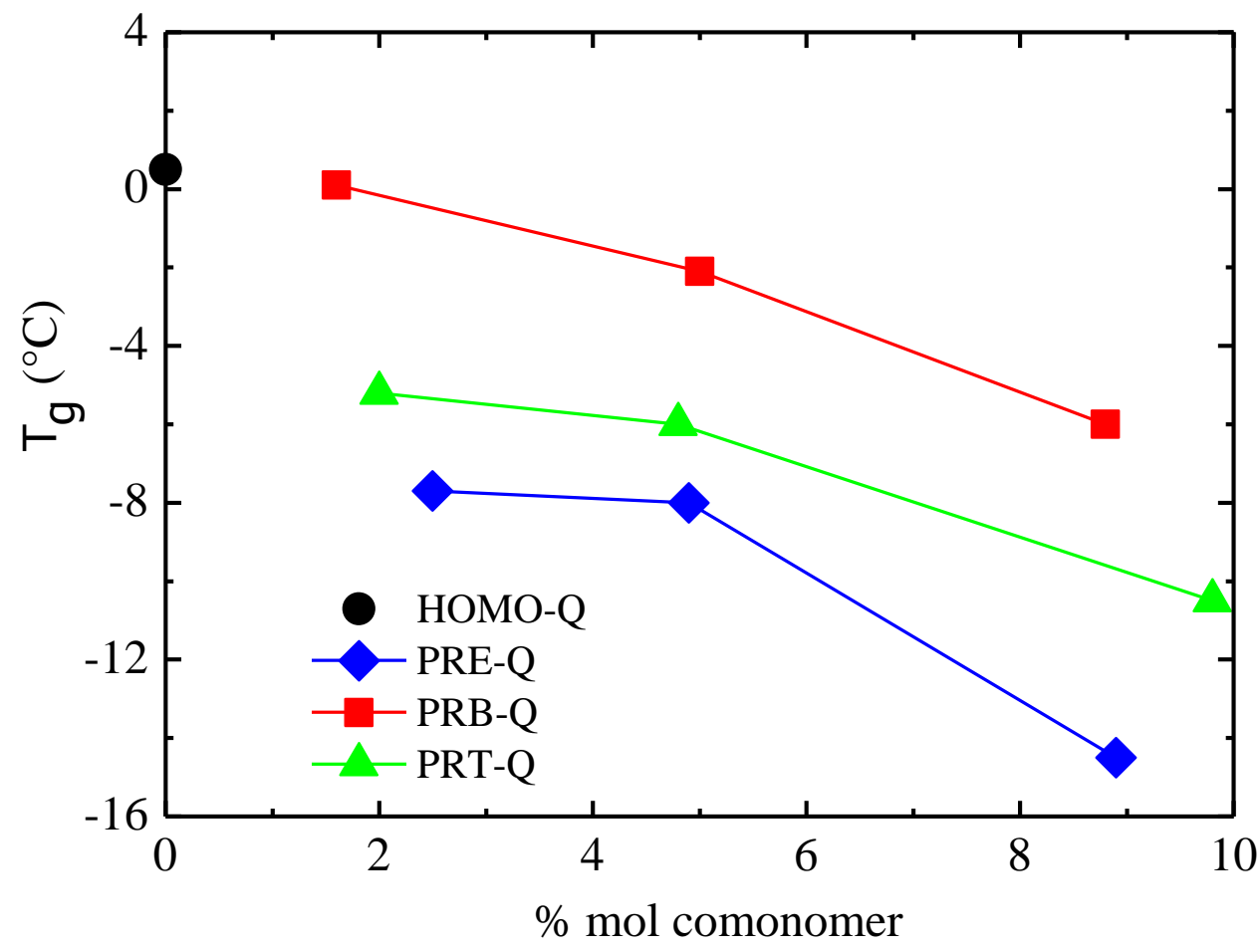

Figure8. Variation of $\mathrm{T}_{\mathrm{g}}$ with comonomer content for 1-butene copolymers, ethylene copolymers and terpolymers. 

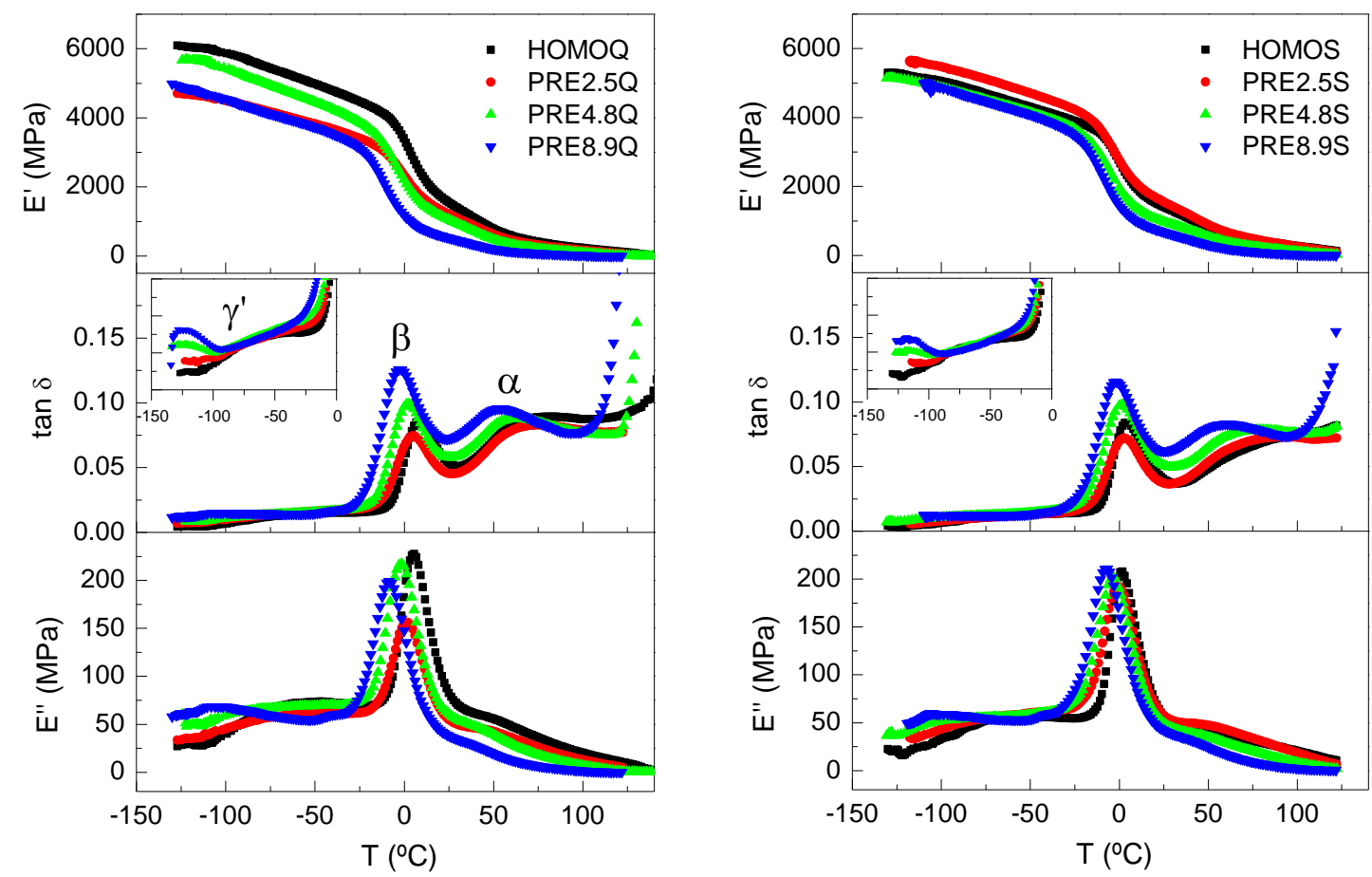

Figure 9. Mechanodynamical curves (at $3 \mathrm{~Hz}$ ) for ethylene copolymers with $\mathrm{Q}$ (left) and $\mathrm{S}$ (right) thermal treatment. 

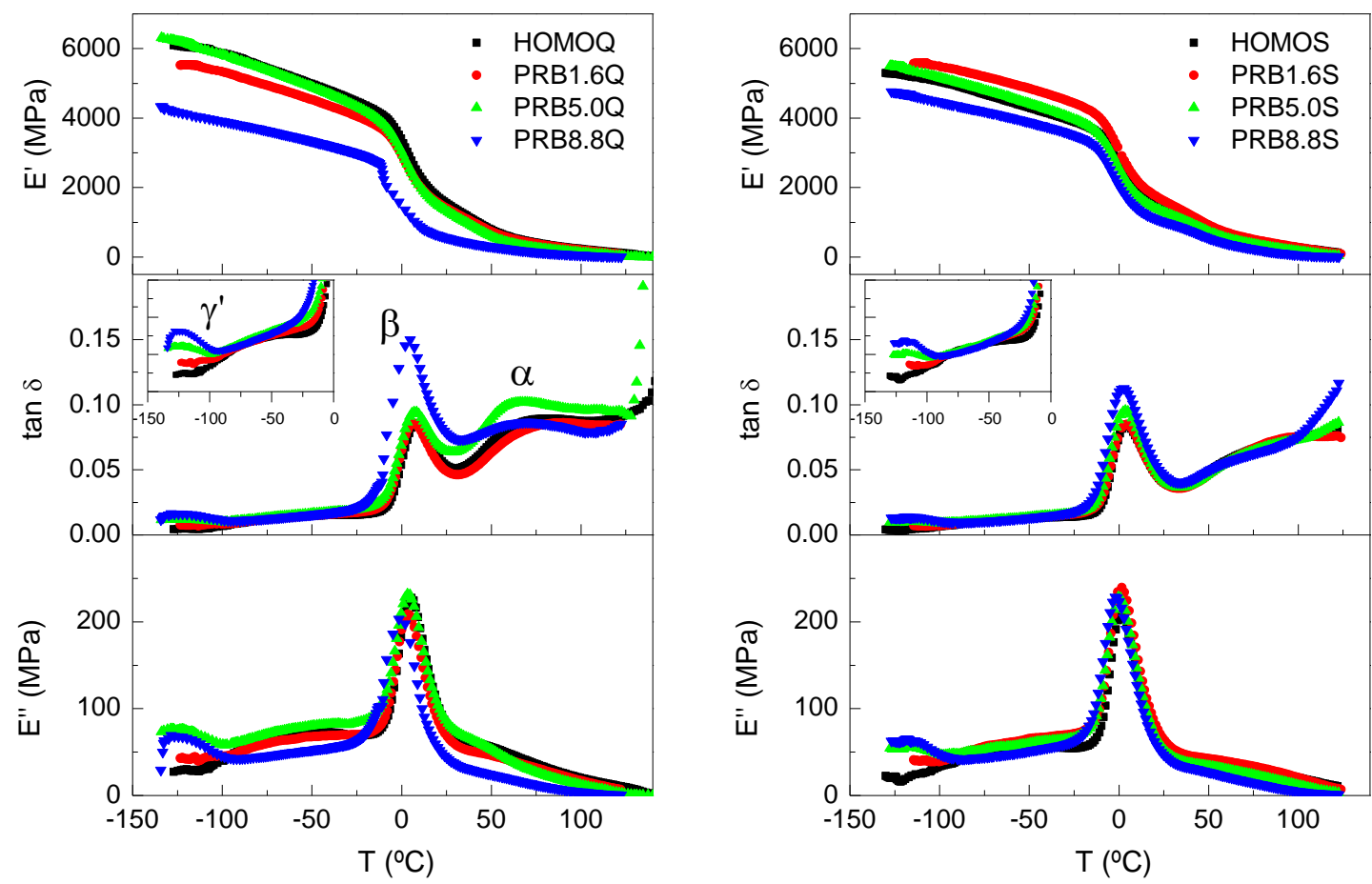

Figure 10. Mechanodynamical curves (at $3 \mathrm{~Hz}$ ) for 1-butene copolymers with Q (left) and $\mathrm{S}$ (right) thermal treatment. 

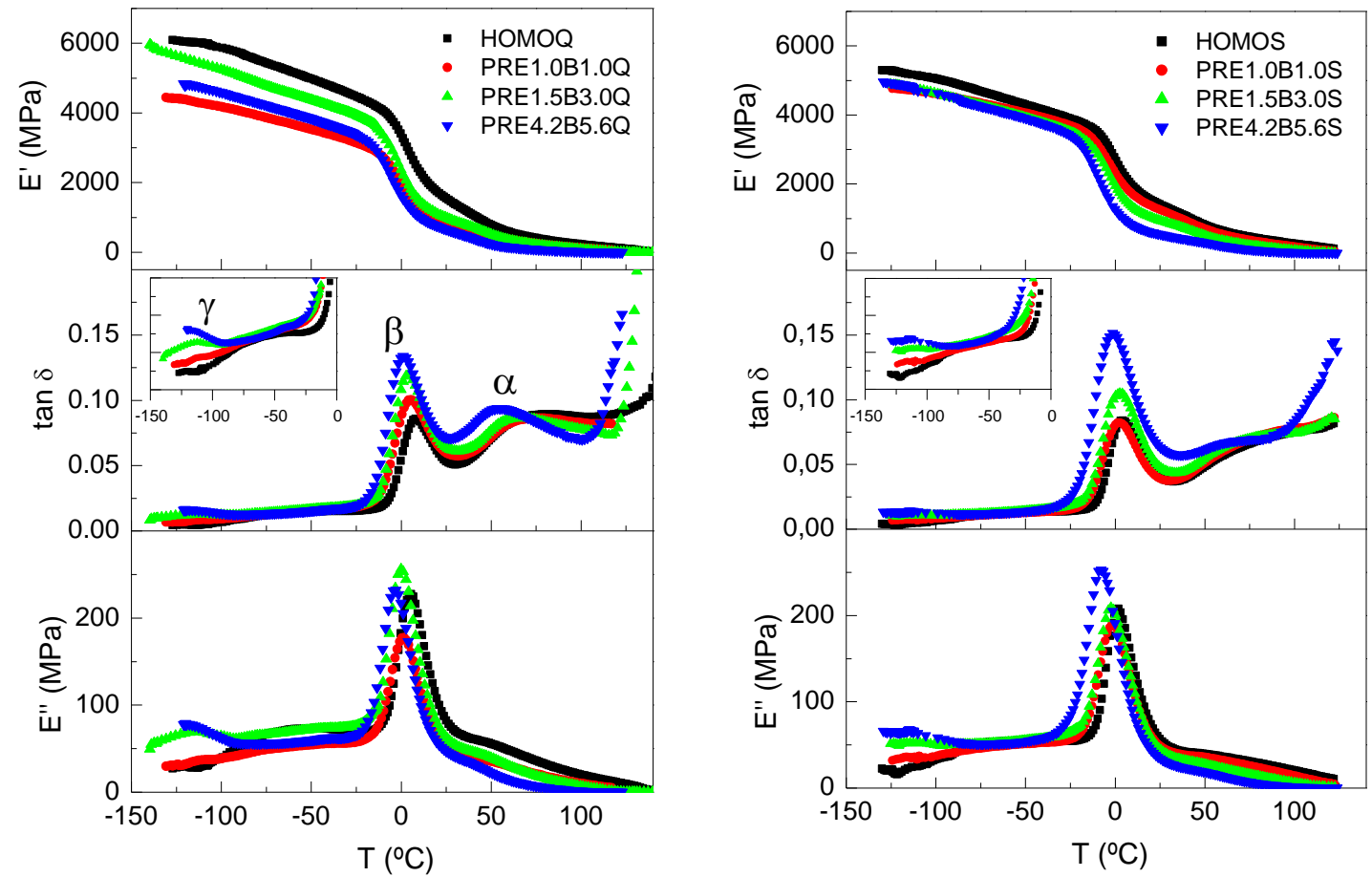

Figure 11. Mechanodynamical curves (at $3 \mathrm{~Hz}$ ) for terpolymers with Q (left) and $\mathrm{S}$ (right) thermal treatment. 


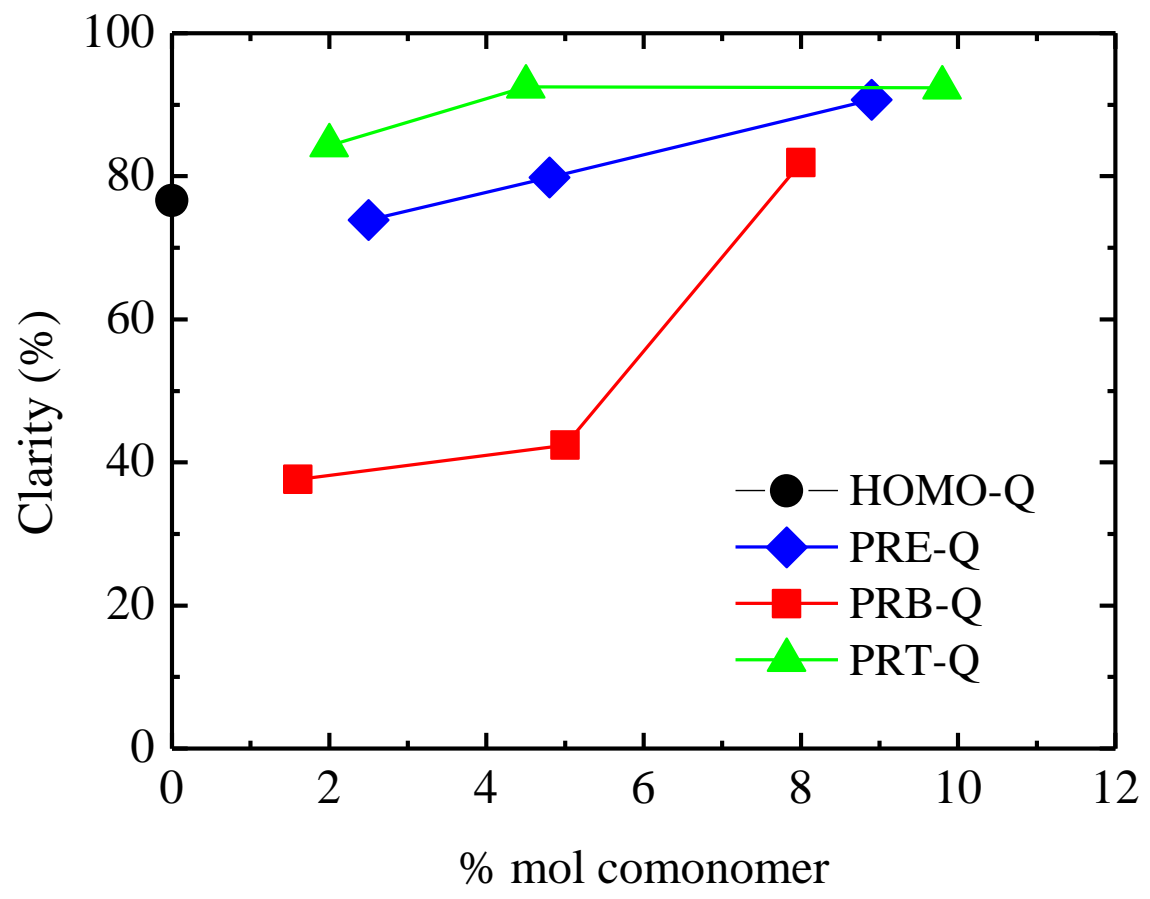

Figure 12. Variation of clarity with comonomer content for 1-butene copolymers, ethylene copolymers and terpolymers. 